\title{
Rapid Publication
}

\section{The Expression of TNF $\alpha$ by Human Muscle Relationship to Insulin Resistance}

\author{
Mehrnoosh Saghizadeh, ${ }^{\star}$ John M. Ong, ${ }^{*}$ W. Timothy Garvey, ${ }^{\ddagger}$ Robert R. Henry, ${ }^{\S}$ and Philip A. Kern \\ *Department of Medicine, Cedars-Sinai Medical Center and University of California, Los Angeles, Los Angeles, California 90048; \\ ${ }^{\ddagger}$ Department of Medicine, Medical University of South Carolina, Charleston, South Carolina 29403; ${ }^{\S}$ Department of Medicine, \\ VA Medical Center and University of California, San Diego, San Diego, California 92161; and $\|^{D e p a r t m e n t ~ o f ~ M e d i c i n e, ~ V A ~ M e d i c a l ~}$ \\ Center and University of Arkansas for Medical Sciences, Little Rock, Arkansas 72205
}

\begin{abstract}
$\mathrm{TNF} \alpha$ is overexpressed in the adipose tissue of obese rodents and humans, and is associated with insulin resistance. To more closely link TNF expression with whole body insulin action, we examined the expression of TNF by muscle, which is responsible for the majority of glucose uptake in vivo. Using RT-PCR, TNF was detected in human heart, in skeletal muscle from humans and rats, and in cultured human myocytes. Using competitive RT-PCR, TNF was quantitated in the muscle biopsy specimens from 15 subjects whose insulin sensitivity had been characterized using the glucose clamp technique. TNF expression in the insulin resistant subjects and the diabetic patients was fourfold higher than in the insulin sensitive subjects, and there was a significant inverse linear relationship between maximal glucose disposal rate and muscle TNF $(r=-0.60, P<0.02)$. In nine subjects, muscle cells from vastus lateralis muscle biopsies were placed into tissue culture for $4 \mathrm{wk}$, and induced to differentiate into myotubes. TNF was secreted into the medium from these cells, and cells from diabetic patients expressed threefold more TNF than cells from nondiabetic subjects. Thus, TNF is expressed in human muscle, and is expressed at a higher level in the muscle tissue and in the cultured muscle cells from insulin resistant and diabetic subjects. These data suggest another mechanism by which TNF may play an important role in human insulin resistance. (J. Clin. Invest. 1996. 97:1111-1116). Key words: tumor necrosis factor $\bullet$ non-insulin-dependent diabetes mellitus - insulin resistance - obesity - quantitative reverse transcriptase polymerase chain reaction (RT-PCR)
\end{abstract}

\section{Introduction}

The development of obesity is not completely understood; humans gain weight to variable degrees when presented with excess calories $(1,2)$, suggesting that individuals can defend against obesity. In addition, insulin resistance accompanies

Address correspondence to Philip A. Kern, M.D., ACOS/R\&D, 598/ 151, JLM Memorial Veterans Hospital, 4300 W. 7th Street, Little Rock, AR 72205. Phone: 501-660-2035; FAX: 501-671-2510; E-mail: PAKern@AOL.com

Received for publication 19 September 1995 and accepted in revised form 13 December 1995.

The Journal of Clinical Investigation

Volume 97, Number 4, February 1996, 1111-1116 nearly all patients who become obese, yet the relationship between adiposity and insulin sensitivity is not clear. One possible etiology for the insulin resistance of obesity is the production of the cytokine tumor necrosis factor $\alpha(\mathrm{TNF} \alpha)$.

Several studies have described the production of TNF $\alpha$ by adipose tissue and demonstrated higher expression in the adipose tissue of insulin resistant, genetically obese rodents $(3,4)$. These observations in rodents were essentially confirmed by recent human studies, which demonstrated elevated TNF expression in the adipose tissue of obese subjects, and decreased expression following weight loss $(5,6)$. Since TNF $\alpha$ is known to induce insulin resistance in 3T3-L1 cells (7), TNF $\alpha$ could function in an autocrine fashion to regulate insulin sensitivity in adipocytes. In an attempt to reverse insulin resistance, a soluble TNF receptor- $\operatorname{IgG}$ chimeric protein was infused into $f a / f a$ rats, resulting in an increase in insulin-stimulated glucose uptake, along with an increase in autophosphorylation of the insulin receptor and insulin receptor substrate 1 (IRS-1) $(3,8)$.

These studies lead to several provocative conclusions regarding the interactions between adipose tissue and muscle. Adipose tissue expressed higher levels of TNF, and the antiTNF infusion in the animals resulted in an increase in glucose disposal (3). Because muscle accounts for most in vivo glucose disposal (9), these data suggested that muscle responded to anti-TNF treatment. In addition, the anti-TNF infusion resulted in an improvement in insulin receptor phosphorylation in both adipose tissue and muscle (10). There are several possibilities for these effects on muscle. As suggested by Hotamisligil and Spiegelman (4), TNF produced by the adipose tissue in, or surrounding, muscle may have caused insulin resistance in muscle, and this peri-muscular adipose TNF may have been inhibited by the anti-TNF antibodies. On the other hand, muscle, like adipose tissue, may itself express TNF, which would then function in an autocrine fashion to inhibit insulin action.

As described herein, we have successfully measured TNF expression in human and rat muscle, and demonstrate regulation of muscle TNF during changes in insulin sensitivity. These studies suggest another potential mechanism for the increased insulin resistance associated with obesity.

\section{Methods}

Patients and sample acquisition. Patients were recruited from the outpatient clinics of the Indiana University School of Medicine, the La Jolla VA Medical Center, and Cedars-Sinai Medical Center. This protocol was approved by each institution's respective IRB, and all subjects gave informed consent to the procedures. The characteristics 
of the patients are shown in Tables I and II. In some of the patients, insulin sensitivity was characterized using the hyperinsulinemic euglycemic clamp technique, as described previously $(11,12)$. In brief, the glucose disposal rate was calculated on the basis of the glucose infusion rate during a primed continuous insulin infusion $(600 \mathrm{mU}$. $\mathrm{m}^{-2} \cdot \mathrm{min}^{-1}$ ), corrected for changes in glucose pool size. Hepatic glucose output was assumed to be completely suppressed at the high insulin infusion rate (12). In all subjects, the studies were carried out for at least $3 \mathrm{~h}$, and the glucose infusion rate was stable for the final 60 min of the study. Glucose disposal rates were normalized per kilogram of lean body mass, determined by dual energy x-ray absorptiometry scanning. During the steady-state period, the serum glucose was maintained between 4.4 and $5.0 \mathrm{mM}$, with a coefficient of variation of $<4 \%$. Muscle biopsies were performed in subjects characterized with glucose clamps and used for quantitation of TNF $\alpha$ mRNA; these subject groups are described in Table II. Euglycemic clamp data were not available on the nine subjects recruited for muscle cell cultures, and these subject groups are described in Table I.

The human skeletal muscle samples were all obtained in the fasting state by needle biopsy of the vastus lateralis muscle and immediately frozen in liquid nitrogen. Human heart was obtained from the left ventricular myocardium (interventricular septum, to avoid contamination by epicardial fat) of the explanted heart of transplant recipients. Cell lines (Chinese hamster ovary [CHO], and L6 muscle cells) were obtained from the American Type Culture Collection (Rockville, MD).

Cultured human muscle cells. Cultured cells from human skeletal muscle were obtained from two sources. Fetal myoblasts were obtained commercially (MyoPack ${ }^{\circledR}$-Sk; Clonetics, San Diego, CA) and differentiated into myotubes by the addition of $2 \%$ FBS after cells reached $70 \%$ confluence, according to the instructions supplied by Clonetics. In addition, myocytes were obtained by primary culture from human muscle biopsies, as described previously (13). In brief, each muscle biopsy yielded $250-400 \mathrm{mg}$ of tissue, which was minced and dissociated with three trypsin/EDTA treatments. Cells were pelleted and resuspended in medium (SkGM; Clonetics) with $2 \%$ FBS and cultured in a $5 \% \mathrm{CO}_{2}$ environment. After reaching $70-80 \%$ confluence, these cells were induced to form fused myotubes by changing the medium to DME containing 2\% FBS. Previous studies using fluorescent cell sorting, using an antibody directed against a muscle surface antigen $(5.1 \mathrm{H} 111)(14)$, demonstrated that these cells were $>90 \%$ myoblasts. In addition, these cells responded to insulin with an increase in glucose transport and glycogen synthesis (13).

Measurement of TNF $m R N A$ levels using reverse-transcriptase polymerase chain reaction $(R T-P C R) .{ }^{1}$ To measure muscle TNF expression, a quantitative competitive PCR assay was developed, as described previously (6). Total RNA was extracted from muscle according to the method of Chomczynski and Sacchi (15), and the quality of RNA was verified by ethidium bromide staining of rRNA bands on a minigel. The primer sites for PCR were located at nucleotides 217 to 236, and 426 to 445 of the TNF cDNA. For rat muscle, as well as for cell lines derived from rodents, slightly different primers were used. The upstream primer was GCC ATT GGC CAG GAG GGC, and the downstream primer was CGC CAC CAC GCT CTT CTG. $0.4 \mu \mathrm{g}$ of total RNA were added to increasing quantities of a cRNA construct, which contained a 49-bp deletion (16). After the reverse transcriptase reaction, PCR was performed for 35 cycles at $67^{\circ} \mathrm{C}$, and the resulting ethidium bromide-stained gel was imaged using an Imagestore 5000 scanner, and analyzed using the Gelbase/Gelblot software (Ultraviolet Products, Ltd., San Gabriel, CA). The ratio of TNF product/cRNA standard was plotted against the number of copies of cRNA added, to yield the equivalence point between cRNA and TNF mRNA. Data were expressed as the "number of copies"/ $\mu \mathrm{g}$ of

1. Abbreviations used in this paper: BMI, body mass index; GDR, glucose disposal rate; NIDDM, non-insulin dependent diabetes mellitus; $\mathrm{RT}$, reverse transcriptase.

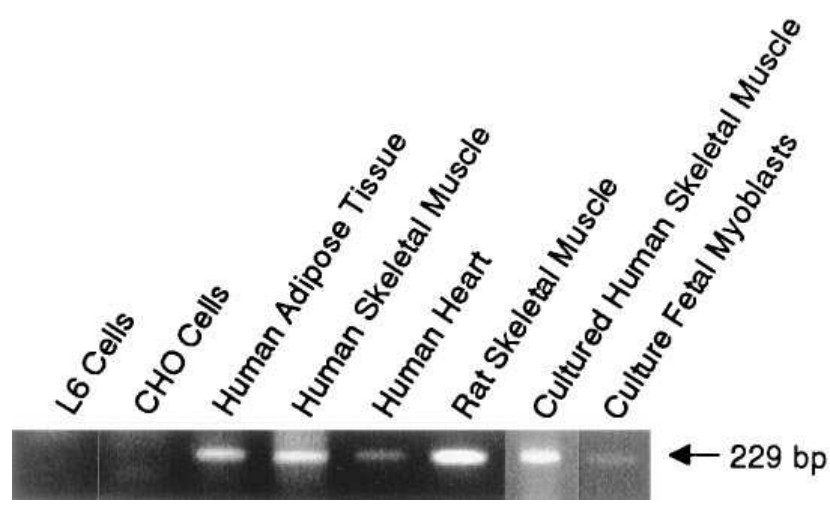

Figure 1. TNF mRNA in muscle cells and tissue. Using RT-PCR, the predicted 229-bp TNF fragment was demonstrated in total RNA extracted from human skeletal and heart muscle, rat muscle (soleus), cultured human myoblasts and cultured myocytes from human muscle biopsies (see Methods). Negative controls included CHO cells, and L6 cells.

total RNA, where "number of copies" refers to the number of copies of the cRNA added. PCR was negative when the reaction was performed without prior RT reaction, indicating a lack of contamination.

Western blotting of TNF protein. TNF was identified in the medium of cultured human muscle cells by Western blotting, using methods described previously (6). Cells were grown to confluence and differentiated into myocytes by the addition of DME containing $2 \%$ Fetal bovine serum. Serum-free medium was added and conditioned medium was collected $2 \mathrm{~h}$ later. Medium was concentrated 10-fold using Centricon Concentrators (Centricon-3; Amicon, Inc., Beverly, MA), and was then analyzed under denaturing conditions on a $15 \%$ SDS polyacrylamide gel. After transfer to nitrocellulose, the membrane was blotted with a 1:2,000 dilution of rabbit anti-TNF antiserum (generously provided by Dr. Carl Grunfeld), followed by biotinylated anti-rabbit IgG (Sigma Chemical Co.), and streptavidinperoxidase (Promega, Madison, WI). The blot was developed with a chemoluminescent peroxidase substrate (Promega). Quantitation was performed by scanning the blot, and comparison with the Western blot image of known TNF standards.

Statistics. All data were analyzed non-parametrically, using the Wilcoxon matched-paired sign rank test for paired data, and the Mann-Whitney test for non-paired data. Linear regressions were performed using the Spearman rank-order correlation test.

\section{Results}

To determine whether TNF was expressed in human muscle, RNA was extracted from a variety of muscle sources and RTPCR was performed as described in Methods. As shown in Fig. 1, the predicted 229-base fragment for TNF was detected in human skeletal and heart muscle, as well as in rat skeletal muscle. Because muscle contains other cells besides myocytes, TNF mRNA was measured in cultured myocytes. As shown in Fig. 1, the TNF mRNA was detected in cultured myoblasts, as well as in myocytes cultured from human muscle biopsies, as described in Methods. Cells that contained no detectable TNF using these methods included L6 cells, which is a rat muscle cell line, and CHO cells.

Fig. 2 illustrates the use of quantitative RT-PCR for the measurement of TNF mRNA from cultured myocytes. RNA was extracted from myocytes prepared from control and diabetic subjects, and added to increasing quantities of the TNF 
A

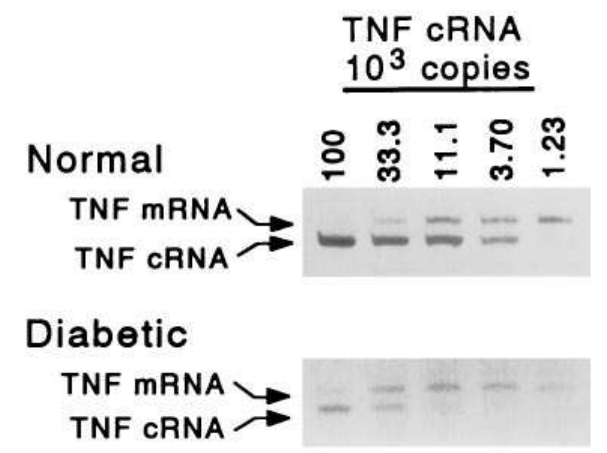

B

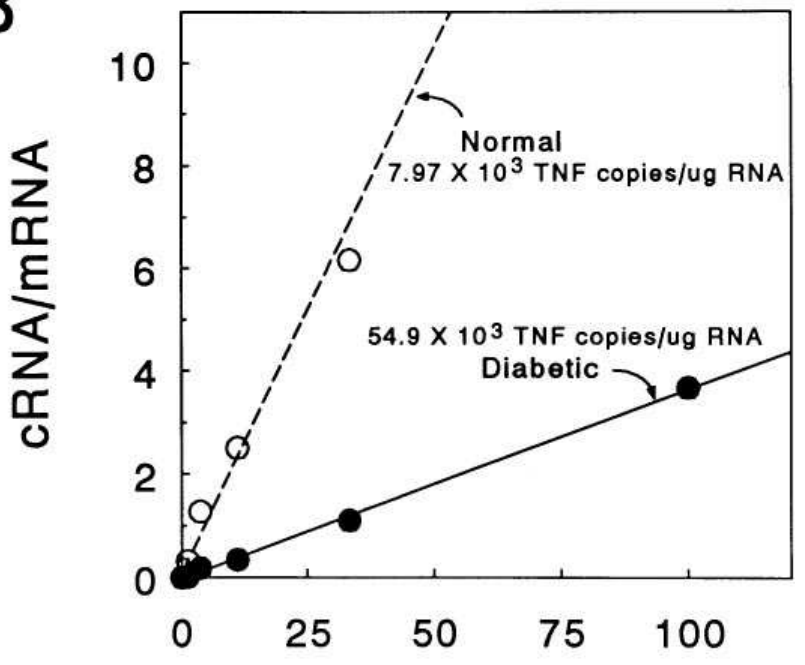

cRNA $\left(10^{3}\right.$ copies $)$

Figure 2. Quantitation of TNF mRNA in muscle using RT-PCR. Total RNA was extracted from myocytes cultured from a normal subject, and a subject with diabetes. $(A)$ Total RNA from each culture was added to increasing quantities (as indicated) of a cRNA construct that contained primer sites for human TNF $\alpha$. RT-PCR of this cRNA construct yielded a product that was 49 nucleotides shorter than the PCR product generated from native human TNF $\alpha$ mRNA, and which could therefore be distinguished on the gel. $(B)$ The ratio of cRNA standard/TNF product was plotted against the number of copies of cRNA added, to yield the equivalence point between cRNA and TNF mRNA. This figure is the plot of the gels from $A$. The equivalence point for the normal (nondiabetic) subject was $4.2 \times 10^{3}$ copies, and for the diabetic patient the equivalence point was $27 \times 10^{3}$ copies, which refers to the number of copies of the cRNA added. Data were expressed as the "number of copies"/ $\mu \mathrm{g}$ of total RNA, which yielded the values shown $\left(7.97 \times 10^{3}\right.$, and $54.9 \times 10^{3}$ copies $/ \mu \mathrm{g}$ total RNA for normal and diabetic, respectively).

cRNA, followed by RT-PCR. The PCR products derived from the cRNA and TNF mRNA were easily distinguished on the gel, and the ratio of the two products increased linearly with addition of cRNA to the reaction. The equivalence point, at which the amount of added cRNA-product was equal to the amount of mRNA-product, was determined and expressed as "number of copies"/ $\mu \mathrm{g}$ of total RNA, where "number of copies" refers to the number of copies of the cRNA added. As can

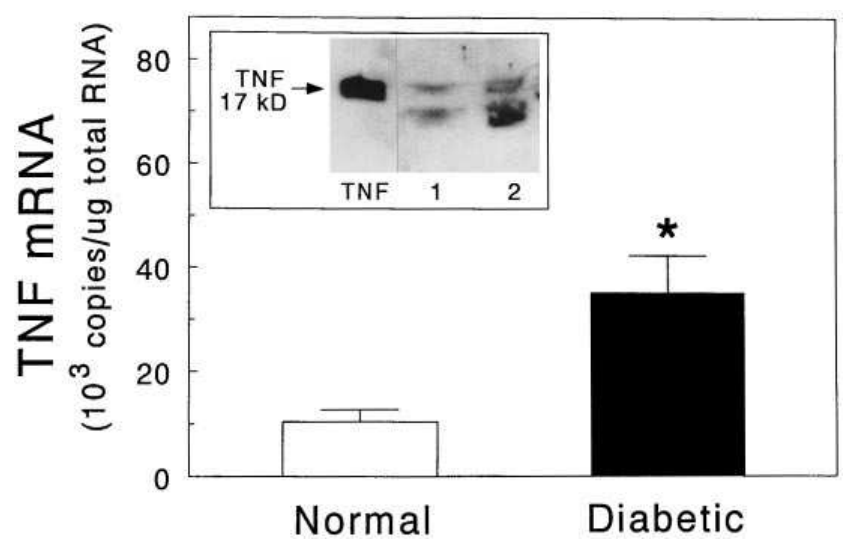

Figure 3. TNF mRNA levels in myocytes cultured from muscle biopsies of normal and diabetic subjects. Data are expressed in relation to copies of cRNA added/ $\mu$ g total RNA. (Inset) TNF secretion into the medium. Western blot of TNF from cultured muscle cells. Purified TNF ( $1 \mathrm{ng}$ ) is shown alongside the medium from myocyte cultures from a normal (lane 1 ) and a diabetic (lane 2 ) subject. ${ }^{*} P<0.05$ vs. normal.

be seen, the amount of TNF mRNA in the myocytes from the diabetic patient was higher than the TNF mRNA in the normal subject.

Additional subjects were recruited for muscle biopsy and subsequent primary culture of myocytes. The description of these nine subjects ( 5 nondiabetic and 4 diabetic) is shown in Table I. There was no difference in body mass index (BMI) between the control and diabetic subjects, and serum glucose, $\mathrm{Hgb} \mathrm{A}_{1} \mathrm{C}$, and insulin levels were higher in the diabetics, as expected. After muscle biopsy, cells were placed into culture for $4 \mathrm{wk}$, and then differentiated into fused myotubes, as described in Methods. TNF mRNA expression was measured using RT-PCR, as described above. As shown in Fig. 3, myocytes cultured from diabetic patients contained significantly more TNF mRNA than myocytes from nondiabetic subjects. To demonstrate that the TNF protein was produced by these cells, the conditioned medium from these cells was collected, concentrated, and analyzed by Western blotting. As shown in Fig. 3 (inset), the $17-\mathrm{kD}$ TNF band was identified from the cultured human muscle cells. In addition to the $17-\mathrm{kD}$ band, a fastermigrating species was identified, which probably represented TNF breakdown product. The Western blot images were scanned and compared to the TNF standard on the gel. Medium TNF immunoreactivity was $6.77 \pm 0.01 \mathrm{ng} / \mathrm{ml}$ in cultures from nondiabetic subjects, and was $14.03 \pm 0.55 \mathrm{ng} / \mathrm{ml}$ in cultures from diabetic patients $(P<0.01)$.

In addition to measuring TNF in cultured myocytes, TNF was measured in the muscle tissue of 15 subjects, who covered a spectrum of insulin sensitivity, as defined by euglycemic clamping. As shown in Table II, five of these subjects were insulin sensitive, with a mean, maximally stimulated glucose disposal rate (GDR) of $18.4 \pm 0.7 \mathrm{mg} / \mathrm{kg}$ per minute, whereas five subjects were nondiabetic but relatively insulin resistant (mean GDR $10.2 \pm 0.5 \mathrm{mg} / \mathrm{kg}$ per minute), and five subjects had noninsulin-dependent diabetes mellitus (NIDDM), and a much lower GDR $(6.9 \pm 1.5 \mathrm{mg} / \mathrm{kg}$ per minute). As expected, the insulin resistant and diabetic subjects had higher fasting insulin levels, and the diabetic subjects had higher fasting blood glucose levels, and were more obese. 
Table I. Subjects for Myocyte Primary Culture

\begin{tabular}{|c|c|c|c|c|c|c|c|}
\hline & $n$ & $\mathrm{M} / \mathrm{F}$ & Age & Insulin & FBG & $\mathrm{Hgb} \mathrm{A}_{1} \mathrm{C}$ & BMI \\
\hline & & & $y r$ & $\mu U / m l$ & $m g \%$ & $\%$ & $\mathrm{~kg} / \mathrm{m}^{2}$ \\
\hline Nondiabetic & 5 & $5 / 0$ & $46 \pm 3$ & $11.2 \pm 2.7$ & $97.4 \pm 3.8$ & $5.8 \pm 2.2$ & $30.0 \pm 3.2$ \\
\hline Diabetic & 4 & $4 / 0$ & $55 \pm 5$ & $27.5 \pm 12.9 *$ & $183 \pm 26.2^{*}$ & $9.6 \pm 0.3 *$ & $30.8 \pm 1.9$ \\
\hline
\end{tabular}

$* P<0.05$ vs. nondiabetic

TNF mRNA levels were measured from the muscle biopsy specimens from each subject. As shown in Fig. 4, TNF mRNA levels were significantly higher in both the insulin resistant subjects, and the diabetic subjects. When the relationship between in vivo insulin action, as represented by the maximal glucose disposal rate, and muscle TNF expression was analyzed, there was a significant linear relationship. As shown in Fig. 5, increasing muscle TNF expression was associated with a decreased in vivo glucose disposal rate $(r=-0.60, P<0.02)$. Thus, there was increased expression of TNF in both cultured myocytes, and in muscle tissue from subjects with diabetes and insulin resistance.

\section{Discussion}

TNF is a cytokine produced in large quantities by macrophages, and has long been associated with the cachexia of cancer and AIDS because of its many catabolic actions (17). In adipocytes, these catabolic actions include a decrease in the activity of lipoprotein lipase (LPL) $(18,19)$, a decrease in the expression of the glucose transporter Glut4 (20), and an increase in lipolysis, suggesting an increase in the activity of hormone sensitive lipase (21). Recent studies have demonstrated that TNF is expressed in adipose tissue, and is expressed at higher levels in the adipose tissue of obese rodents and humans $(3,5$, $6)$. Therefore, the production of TNF by adipose tissue could be a local regulator of fat cell size, and the overproduction of TNF in the adipocytes of obese mammals could limit adipocyte size through some combination of catabolic actions.

Additional studies have suggested that TNF is important in the development of insulin resistance, both in obesity, and in NIDDM. When a soluble TNF binding protein was infused into $f a / f a$ rats, which have high levels of adipose tissue TNF, there was a 2-3-fold increase in insulin-stimulated glucose uptake, along with improved insulin receptor autophosphorylation in both adipose tissue and muscle $(3,10)$. Since muscle is the main determinant of insulin-stimulated glucose uptake, these findings indicated that the systemic inhibition of TNF affected in vivo insulin action, and therefore likely involved insulin action in muscle. There are several possibilities to explain these changes involving muscle. Adipose tissue TNF may be secreted into plasma, and plasma TNF may affect muscle insulin responsiveness. However, TNF levels in plasma are very low, and cannot be reproducibly measured, even in patients with obesity or metastatic cancer $(5,17,22)$. Therefore, adipose TNF may not affect muscle in a traditional humoral fashion. Another possibility is an indirect effect, where adipose TNF triggers other events, which ultimately lead to decreased muscle insulin action. It is also possible that certain adipose tissue depots, which are in close proximity to muscle, secrete TNF, which then affect muscle glucose transport in a paracrine fashion (4).

As described herein, TNF was expressed by both rat and human muscle, and was also expressed by muscle cells in culture. These data suggest that TNF could have been produced by muscle cells and functioned in an autocrine fashion to inhibit muscle glucose transport. Hence, when TNF binding protein was infused into $f a / f a$ rats $(3,10)$, it may have inhibited muscle TNF, as well as inhibit TNF from other sources, such as adipose tissue. However, in a previous study, TNF mRNA was not detected in rat muscle by Northern blot (3). We demonstrated the presence of both the TNF mRNA, as well as the TNF protein in cultured cells. The TNF detected in muscle could not have been from contamination from adipose cells. TNF was detected in heart muscle and rat skeletal muscle, both of which were free of adipose tissue, and in cultured muscle cells. Although the muscle cells in culture contained $>90 \%$ myocytes (13), it is possible that the cell of origin for TNF expression was a cell in muscle other than a myocyte. The level of expression of TNF by muscle is lower than that in adipose tissue, and therefore RT-PCR was used to measure TNF mRNA levels in muscle.

TNF expression was increased in the muscle biopsy samples from subjects with insulin resistance, and there was a significant inverse relationship between TNF mRNA levels and GDR. It is important to note that muscle TNF was increased in insulin resistant non-diabetics, as well as in subjects with established NIDDM. Therefore, the elevated muscle TNF cannot be a result of hyperglycemia and the diabetic milieu. This relationship between TNF and GDR was dependent on the inclu-

Table II. Subjects for Muscle Biopsy

\begin{tabular}{|c|c|c|c|c|c|c|c|c|}
\hline & $n$ & $\mathrm{M} / \mathrm{F}$ & Age & GDR & Insulin & FBG & BMI & Body fat \\
\hline & & & $y r$ & $\mathrm{mg} / \mathrm{kg}$ per min & $\mu U / m l$ & $m g \%$ & $\mathrm{~kg} / \mathrm{m}^{2}$ & $\%$ \\
\hline Normal, insulin-sensitive & 5 & $3 / 2$ & $38.8 \pm 2.3$ & $18.4 \pm 0.7$ & $5.8 \pm 0.7$ & $83.6 \pm 2.5$ & $26.7 \pm 2.2$ & $30.4 \pm 7.6$ \\
\hline Normal, insulin-resistant & 5 & $5 / 0$ & $37.0 \pm 4.6$ & $10.2 \pm 0.5^{\ddagger}$ & $16.6 \pm 8.7$ & $91.8 \pm 0.9^{*}$ & $29.4 \pm 1.4$ & $26.2 \pm 1.8$ \\
\hline Diabetic & 5 & $3 / 2$ & $42.2 \pm 1.9$ & $6.9 \pm 1.5^{\ddagger}$ & $16.8 \pm 4.7$ & $199.3 \pm 35.5^{+}$ & $39.1 \pm 2.2^{\ddagger}$ & $37.8 \pm 4.5$ \\
\hline
\end{tabular}

$* P<0.05$ vs. normal, insulin sensitive; ${ }^{\ddagger} P<0.02$ vs. normal, insulin sensitive. 


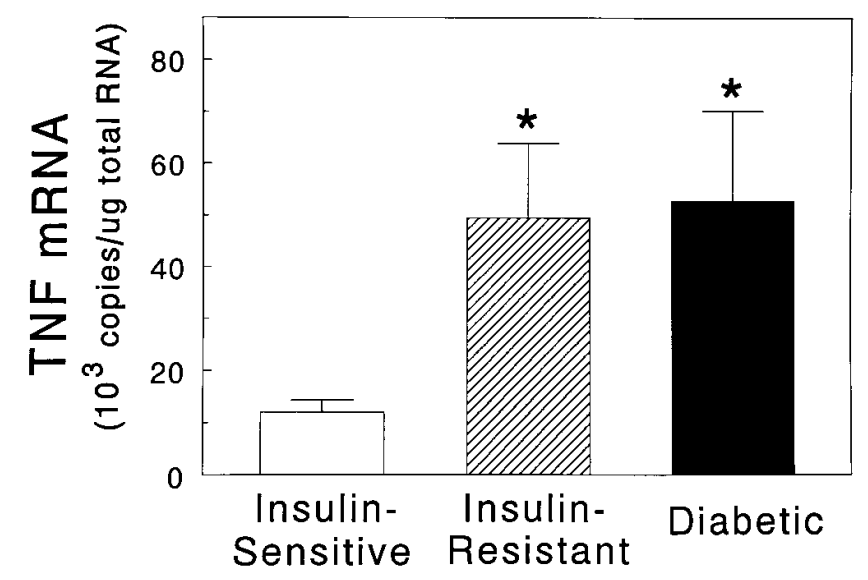

Figure 4. TNF mRNA expression by human muscle. TNF mRNA levels in muscle biopsy specimens from insulin sensitive, insulin resistant (nondiabetic), and diabetic subjects. ${ }^{*} P<0.05$ vs. normal.

sion of the normal, insulin sensitive subjects, as there was not a significant correlation with TNF when just the insulin resistant subjects were considered. In addition, TNF expression was also elevated in muscle cells cultured from obese diabetics, when compared to obese nondiabetics. The diabetic subjects were likely more insulin resistant than the nondiabetic controls, as evidenced by the elevated blood insulin levels. These cells had been removed from the diabetic environment and in culture for $4 \mathrm{wk}$, yet they still displayed elevated TNF.

It is tempting to speculate that disordered TNF regulation in muscle may be an important part of insulin resistance. Al-

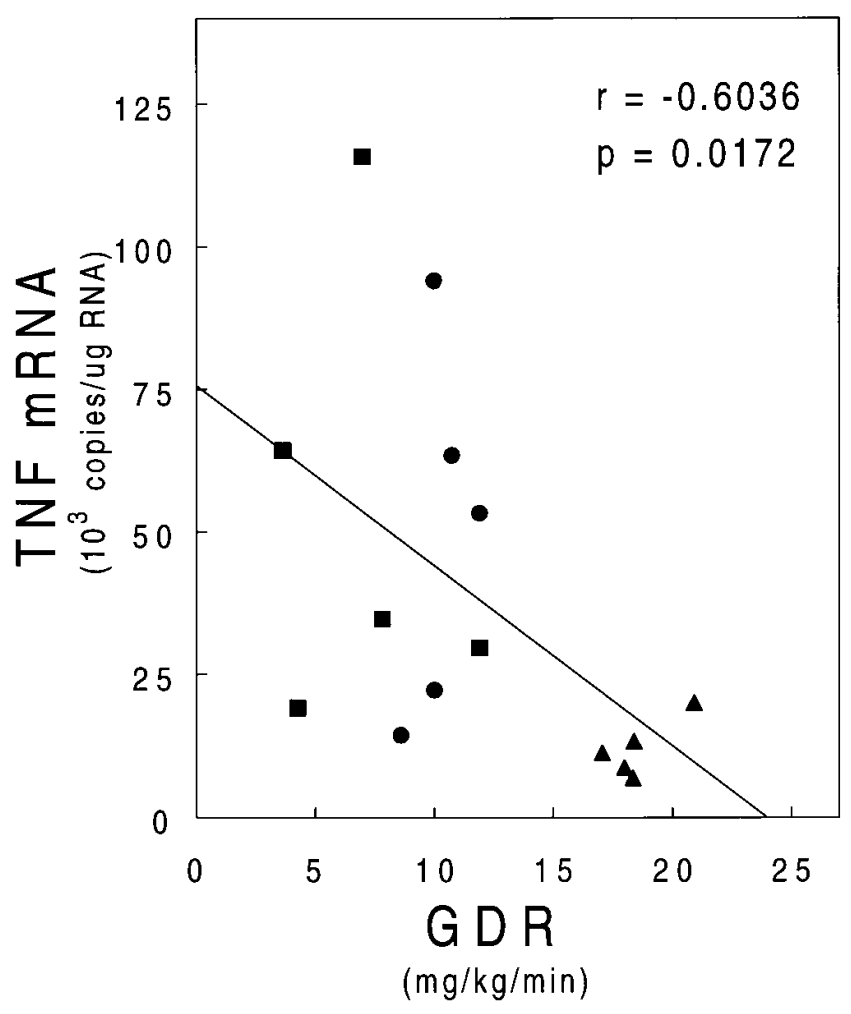

Figure 5. Relationship between muscle TNF expression and insulin sensitivity. There was an inverse relationship between TNF mRNA and GDR. GDR was expressed as $\mathrm{mg} / \mathrm{kg}$ per minute. ( $\Delta$ ) Insulin sensitive; (๑) insulin resistant; (ם) diabetic. though the levels of TNF expression by muscle were low, they may be sufficient to cause insulin resistance in an autocrine manner in muscle. Because cultured muscle cells from diabetics continued to express higher levels of TNF, and because insulin resistant nondiabetics overexpressed TNF in muscle, these data are consistent with TNF as a primary, or as an early pathophysiologic marker of the insulin resistant state, and could be part of the complex genetic syndrome characterized phenotypically by obesity, insulin resistance, and NIDDM. On the other hand, it is possible that the elevated TNF expression is a response to the insulin resistant state, and that cells maintain this overexpression when cultured.

In summary, TNF was expressed by human muscle and myocytes in culture, and TNF expression was higher in the muscle of subjects with insulin resistance and NIDDM. These data suggest an important role for TNF $\alpha$ in the pathogenesis of human insulin resistance, as occurs in obesity and diabetes.

\section{Acknowledgments}

We wish to acknowledge the assistance of Diane Vu, Gouri Ranganathan, Lidia Maranu, and Douglas Laramore.

This work was supported by grants DK-39176 and DK-38765 from the National Institutes of Health, a Grant-in-Aid from the American Heart Association, and a Merit Review grant from the Department of Veterans Affairs. This work was done during the tenure of an Established Investigatorship from the American Heart Association.

\section{References}

1. Sims, E.A.H. 1976. Experimental obesity, dietary induced thermogenesis and their clinical implications. Clin. Endocrinol. Metab. 5:377-395.

2. Bouchard, C., A. Tremblay, J.-P. Després, A. Nadeau, P.J. Lupien, G. Theriault, J. Dussault, S. Moorjani, S. Pinault, and G. Fournier. 1990. The response to long-term overfeeding in identical twins. N. Engl. J. Med. 322:14771482.

3. Hotamisligil, G.S., N.S. Shargill, and B.M. Spiegelman. 1993. Adipose expression of tumor necrosis factor-a: Direct role in obesity-linked insulin resistance. Science (Wash. DC). 259:87-91.

4. Hotamisligil, G.S., and B.M. Spiegelman. 1994. Tumor necrosis factor a: a key component of the obesity-diabetes link. [Review]. Diabetes. 43:1271-1278.

5. Hotamisligil, G.S., P. Arner, J.F. Caro, R.L. Atkinson, and B.M. Spiegelman. 1995. Increased adipose tissue expression of tumor necrosis factor-alpha in human obesity and insulin resistance. J. Clin. Invest. 95:2409-2415.

6. Kern, P.A., M. Saghizadeh, J.M. Ong, R.J. Bosch, R. Deem, and R.B. Simsolo. 1995. The expression of tumor necrosis factor in human adipose tissue. Regulation by obesity, weight loss, and relationship to lipoprotein lipase. $J$. Clin. Invest. 95:2111-2119.

7. Hotamisligil, G.S., D.L. Murray, L.N. Choy, and B.M. Spiegelman. 1994. Tumor necrosis factor a inhibits signaling from the insulin receptor. Proc. Natl. Acad. Sci. USA. 91:4854-4858.

8. Hotamisligil, G.S., A. Budavari, D. Murray, and B.M. Spiegelman. 1994. Reduced tyrosine kinase activity of the insulin receptor in obesity-diabetes. Central role of tumor necrosis factor-alpha. J. Clin. Invest. 94:1543-1549.

9. DeFronzo, R.A., E. Jacot, E. Jequier, E. Maeder, J. Wahren, and J.P. Felber. 1981. The effect of insulin on the disposal of intravenous glucose. Results from indirect calorimetry and hepatic and femoral venous catheterization. Diabetes. 30:1000-1007.

10. Hotamisligil, G.S., A. Budavari, D. Murray, and B.M. Spiegelman. 1994 Reduced tyrosine kinase activity of the insulin receptor in obesity-diabetes. Central role of tumor necrosis factor-a. J. Clin. Invest. 94:1543-1549.

11. DeFronzo, R.A., J.D. Tobin, and R. Andres. 1979. Glucose clamp technique: a method for quantifying insulin secretion and resistance. Am. J. Physiol. 237:E214-E223.

12. Garvey, W.T., J.M. Olefsky, J. Griffin, R.F. Hamman, and O.G. Kolterman. 1985. The effect of insulin treatment on insulin secretion and insulin action in type II diabetes mellitus. Diabetes. 34:222-234.

13. Henry, R.R., L. Abrams, S. Nikalina, and T.P. Ciaraldi. 1995. Insulin action and glucose metabolism in nondiabetic control and NIDDM subjects. Comparison using human skeletal muscle cell cultures. Diabetes. 44:936-946.

14. Webster, C., G.K. Pavlath, D.R. Parks, F.S. Walsh, and H.M. Blau. 1988. Isolation of human myoblasts with a fluorescence-activated cell sorter. 
Exp. Cell Res. 17:252-265.

15. Chomczynski, P., and N. Sacchi. 1987. Single-step method of RNA isolation by acid guanidinium thiocyanate-phenol-chloroform extraction. Anal. Biochem. 162:156-159.

16. Andus, T., S.R. Targan, R. Deem, and H. Toyoda. 1993. Measurement of tumor necrosis factor alpha mRNA in small numbers of cells by quantitative polymerase chain reaction. Regional Immunol. 5:11-17.

17. Grunfeld, C., and K.R. Feingold. 1992. Seminars in medicine of the Beth Israel Hospital, Boston: Metabolic disturbances and wasting in the acquired immunodeficiency syndrome. N. Engl. J. Med. 327:329-337.

18. Fried, S.K., and R. Zechner. 1989. Cachectin/tumor necrosis factor decreases human adipose tissue lipoprotein lipase mRNA levels, synthesis, and activity. J. Lipid Res. 30:1917-1923.
19. Grunfeld, C., R. Gulli, A.H. Moser, L.A. Gavin, and K.R. Feingold. 1989. Effect of tumor necrosis factor administration in vivo on lipoprotein lipase activity in various tissues of the rat. J. Lipid Res. 30:579-585.

20. Stephens, J.M., and P.H. Pekala. 1991. Transcriptional repression of the GLUT4 and C/EBP genes in 3T3-L1 adipocytes by tumor necrosis factor- $\alpha$. $J$. Biol. Chem. 266:21839-21845.

21. Patton, J.S., H.M. Shepard, H. Wilking, G. Lewis, B.B. Aggarwal, T.E. Eessalu, L.A. Gavin, and C. Grunfeld. 1986. Interferons and tumor necrosis factors have similar catabolic effects on 3T3-L1 cells. Proc. Natl. Acad. Sci. USA. 83:8313-8317.

22. Socher, S.H., D. Martinez, J.B. Craig, J.G. Kuhn, and A. Oliff. 1988. Tumor necrosis factor not detectable in patients with clinical cancer cachexia. $J$. Natl. Cancer Inst. 80:595-598. 